\title{
Bifurcation and Chaos in a Price Game of Irrigation Water in a Coastal Irrigation District
}

\author{
Baogui Xin ${ }^{1,2}$ and Yuting $\mathrm{Li}^{1,3}$ \\ ${ }^{1}$ Nonlinear Science Center, School of Economics and Management, Shandong University of Science and Technology, \\ Qingdao 266590, China \\ ${ }^{2}$ Nonlinear Dynamics and Chaos Group, School of Management, Tianjin University, Tianjin 300072, China \\ ${ }^{3}$ College of Mechanical and Electronic Engineering, Shandong University of Science and Technology, Qingdao 266590, China
}

Correspondence should be addressed to Baogui Xin; xin@tju.edu.cn

Received 8 March 2013; Accepted 17 April 2013

Academic Editor: Qingdu Li

Copyright (C) 2013 B. Xin and Y. Li. This is an open access article distributed under the Creative Commons Attribution License, which permits unrestricted use, distribution, and reproduction in any medium, provided the original work is properly cited.

We propose a price game model of irrigation water in a coastal irrigation district. Then, we discuss the stability and codimension-two period-doubling (flip) bifurcation. Then, the MATLAB package Cl_MatContM is employed to illustrate its numerical bifurcationsbased continuation methods. Lastly, the $0-1$ test algorithm is used to compute the median value of correlation coefficient which can indicate whether the underlying dynamics is regular or chaotic.

\section{Introduction}

Water scarcity is one of the key problems affecting most countries in the world. With a burgeoning population, food price volatility, and climate change, water scarcity would also fuel future global conflict. Water scarcity is exacerbated by the indiscriminate discharge of industrial and municipal wastewater and is likely to affect the supply and demand of grain in the years ahead. Irrigation water availability is decreasing in many places where crop and plant production is taking place. Not only is there no set of efficient technique that can suddenly eliminate water scarcity, but also there is no optimal institutional arrangement for water, and rather it is critical to understand the potential contributions, facilitating conditions, and limitations of each $[1,2]$. One of the important causes of water scarcity is that the demand exceeds a finite supply. All over the world, water regulations have historically focused on supply management. In fact, pricing mechanism may turn the tide against water scarcity by improving the water use efficiency [3-6]. Thereinto, the price game between water oligopolies is an important pricing mechanism. One of the simplest the price games is price game of irrigation water in a coastal irrigation district because there is little demand diversity of the irrigation water type among farmers. It will be considered in this paper.

In recent years, a lot of research works [7-14] have shown that the game theory plays an important role in the economics and management field. Ji et al., Son et al., and Skoulidas et al. [15-17] studied the game model in an electric power market. Mu et al. [18, 19] analyzed the game model in a real estate market. Liu et al. [20] discussed the minority game in a financial market. Gkonis and Psaraftis [21] proposed a game model in the LNG market. Sun and Ma [22] presented a game model in Chinese cold rolled steel market. Sugawara and Omori [23] considered the duopoly in the Japanese airline market. Chung et al. [24] applied the game model into pollution permit markets. Ma and Zhang [25] build a price game in a property insurance market.

Some references [26-32] have reported the complex dynamics of game model, such as bifurcation and chaos. Analyzing bifurcation and chaos is not an easy task for most of researchers. Fortunately, there are many powerful methods for us to study bifurcation and chaos, such as 0-1 test algorithm for chaos [33-38], MATLAB package MatCont series [39-43] for the bifurcation of discrete, and continuous dynamical systems. 


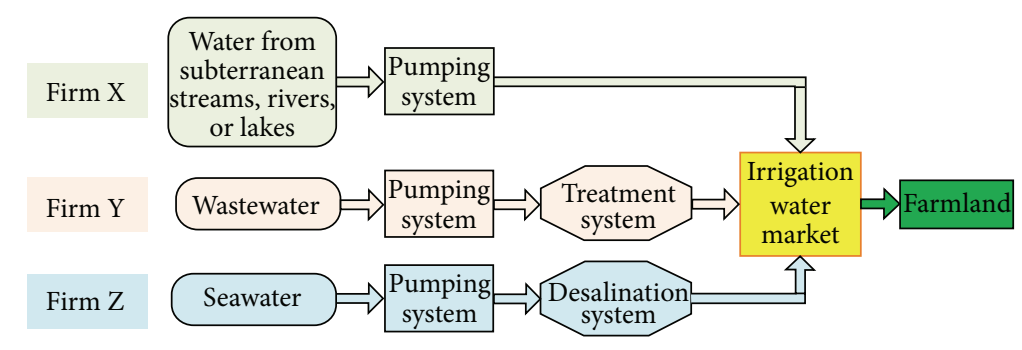

FIGURE 1: Schematic diagram of water supply in the coastal irrigation district.

This paper is organized as follows. In Section 2, a price game model of irrigation water in a coastal irrigation district is presented. In Section 3, the fixed points and their stabilities are studied. In Section 4, codimension-two period-doubling (flip) bifurcation is discussed. In Section 5, the 0-1 test algorithm and continuation methods are employed to validate the main results. Finally, conclusions in Section 6 close the paper.

\section{A Pricing Game Model}

In a coastal irrigation district, water mainly exists in ocean, rivers, lakes, or subterranean streams. But seawater and wastewater cannot directly be used for irrigation because the salt and pollutants will not allow the crops to grow. Generally speaking, groundwater can be directly used as irrigation water, but seawater and wastewater need to be pumped to a desalination plant and a wastewater treatment plant, respectively, and to be treated to be suitable for irrigation. Taking such factors as the freshwater scarcity, the high cost of wastewater treatment, and seawater desalination into consideration, wastewater treatment and seawater desalination have to rely on the help of government subsidies or tax breaks.

Assumption 1. As shown in Figure 1, firms X, Y, and Z are the three water oligopolies of the irrigation water market in the coastal irrigation district. Firm $\mathrm{X}$ supplies irrigation water by directly pumping from rivers, lakes, or subterranean streams, and firm Y supplies irrigation water by wastewater treatment, and firm $\mathrm{Z}$ supplies irrigation water by seawater desalination.

Assumption 2. Firms X, Y, and Z compete with making different price of irrigation water in discrete-time periods $t=0,1,2, \ldots$. Consider that $p_{x_{t}}, p_{y_{t}}$, and $p_{z_{t}}$ represent, respectively, the irrigation water price of firms $\mathrm{X}, \mathrm{Y}$, and $\mathrm{Z}$ during period $t=0,1,2, \ldots$.

Assumption 3. The quantities, in which firms $\mathrm{X}, \mathrm{Y}$, and $\mathrm{Z}$ sell, respectively, $Q_{x_{t}}, Q_{y_{t}}$, and $Q_{z_{t}}$, are linear inverse demand functions determined by the following equations:

$$
\begin{aligned}
& Q_{x_{t}}=a-b p_{x_{t}}+d\left(p_{y_{t}}+p_{z_{t}}\right), \\
& Q_{y_{t}}=a-b p_{y_{t}}+d\left(p_{x_{t}}+p_{z_{t}}\right), \\
& Q_{z_{t}}=a-b p_{z_{t}}+d\left(p_{x_{t}}+p_{y_{t}}\right),
\end{aligned}
$$

where $a, b, d>0$. The parameter $d$ denotes the extent to which a firm's irrigation water is substituted by its rivals' water.

Assumption 4. The cost functions of firms X, Y, and Z have the following linear forms:

$$
C_{x_{t}}=c_{1} Q_{x_{t}}, \quad C_{y_{t}}=c_{2} Q_{y_{t}}, \quad C_{z_{t}}=c_{3} Q_{z_{t}},
$$

where parameters $c_{i}>0(i=1,2,3)$ are marginal costs of the firms $\mathrm{X}, \mathrm{Y}$, and $\mathrm{Z}$, respectively.

Assumption 5. The profit functions of firms X, Y, and Z have the following forms:

$$
\begin{aligned}
\Pi_{x_{t}} & =Q_{x_{t}} p_{x_{t}}-C_{x_{t}} \\
& =\left(p_{x_{t}}-c_{1}\right)\left(a-b p_{x_{t}}+d\left(p_{y_{t}}+p_{z_{t}}\right)\right), \\
\Pi_{y_{t}} & =Q_{y_{t}} p_{y_{t}}+Q_{y_{t}} s_{2}-C_{y_{t}} \\
& =\left(p_{y_{t}}+s_{2}-c_{2}\right)\left(a-b p_{y_{t}}+d\left(p_{x_{t}}+p_{z_{t}}\right)\right), \\
\Pi_{z_{t}} & =Q_{z_{t}} p_{z_{t}}+Q_{z_{t}} s_{3}-C_{z_{t}} \\
& =\left(p_{z_{t}}+s_{3}-c_{3}\right)\left(a-b p_{z_{t}}+d\left(p_{x_{t}}+p_{y_{t}}\right)\right),
\end{aligned}
$$

where $s_{2}$ and $s_{3}>0$ are the intensity coefficients of government support (such as subsidies and tax breaks) for the firms $Y$ and $Z$, respectively.

Assumption 6. Firms X, Y, and Z always make the optimal price decision for the maximal marginal profit in every single period.

The water prices of firms $\mathrm{X}, \mathrm{Y}$, and $\mathrm{Z}$ in period $(t+1)$ are decided by solving the following optimization problem:

$$
\begin{aligned}
& p_{x_{t+1}}=\arg \max _{p_{x}} \prod_{x}\left(p_{x_{t}}, p_{y_{t+1}}^{e_{x}}, p_{z_{t+1}}^{e_{x}}\right), \\
& p_{y_{t+1}}=\arg \max _{p_{y}} \prod_{x}\left(p_{x_{t+1}}^{e_{y}}, p_{y_{t}}, p_{z_{t+1}}^{e_{y}}\right), \\
& p_{z_{t+1}}=\arg \max _{p_{z}} \prod_{x}\left(p_{x_{t+1}}^{e_{z}}, p_{y_{t+1}}^{e_{z}}, p_{z_{t}}\right),
\end{aligned}
$$

where $p_{y_{t+1}}^{e_{x}}$ represents the expectation of firm $\mathrm{X}$ about the water price of firm Y during period $t+1$. Consider that $p_{z_{t+1}}^{e_{x}}$, $p_{x_{t+1}}^{e_{y}}, p_{z_{t+1}}^{e_{y}}, p_{x_{t+1}}^{e_{z}}$, and $p_{y_{t+1}}^{e_{z}}$ may be explained by analogy. 
Assumption 7. Each firm expects that its rivals' water price in period $(t+1)$ will remain the same as in period $(t)$.

Thus,

$$
\begin{gathered}
p_{y_{t+1}}^{e_{x}}=p_{y_{t+1}}^{e_{z}}=p_{y_{t}}, \quad p_{z_{t+1}}^{e_{x}}=p_{z_{t+1}}^{e_{y}}=p_{z_{t}}, \\
p_{x_{t+1}}^{e_{y}}=p_{x_{t+1}}^{e_{z}}=p_{x_{t}} .
\end{gathered}
$$

The margin profits of firms $\mathrm{X}, \mathrm{Y}$, and $\mathrm{Z}$ in period $t$ are given, respectively, by

$$
\begin{aligned}
& \frac{\partial \Pi_{x_{t}}}{\partial p_{x_{t}}}=a-2 b p_{x_{t}}+d\left(p_{y_{t}}+p_{z_{t}}\right)+b c_{1}, \\
& \frac{\partial \Pi_{y_{t}}}{\partial p_{y_{t}}}=a-2 b p_{y_{t}}+d\left(p_{x_{t}}+p_{z_{t}}\right)+b\left(c_{2}-s_{2}\right), \\
& \frac{\partial \Pi_{z_{t}}}{\partial p_{z_{t}}}=a-2 b p_{z_{t}}+d\left(p_{x_{t}}+p_{y_{t}}\right)+b\left(c_{3}-s_{3}\right) .
\end{aligned}
$$

Let (6) be equal to 0 ; one can obtain the reaction functions of firms X, Y, and Z; that is, the optimal water prices are as follows:

$$
\begin{gathered}
p_{x}^{*}=\frac{a+d\left(p_{y}+p_{z}\right)+b c_{1}}{2 b}, \\
p_{y}^{*}=\frac{a+d\left(p_{x}+p_{z}\right)+b\left(c_{2}-s_{2}\right)}{2 b}, \\
p_{z}^{*}=\frac{a+d\left(p_{x}+p_{y}\right)+b\left(c_{3}-s_{3}\right)}{2 b} .
\end{gathered}
$$

Assumption 8. Firm $\mathrm{X}$ uses bounded rationality to make its price decisions with local information based on the marginal profits $\partial \Pi_{x} / \partial p_{x}$ and increase (decrease) its water prices in period $(t+1)$ if the marginal profit is positive (negative) $[8,29,44]$.

The above adjustment mechanism of firm $\mathrm{X}$ has been called myopic by Dixit [45]. The dynamical adjustment mechanism of firm $\mathrm{X}$ can be written as follows:

$$
p_{x_{t+1}}=p_{x_{t}}+\alpha p_{x_{t}} \frac{\partial \Pi_{x_{t}}}{\partial p_{x_{t}}}
$$

where $\alpha>0$ represents the adjustment speed of firm X.

Assumption 9. Firm $\mathrm{Y}$ is an adaptive decision maker and has adaptive expectations. Thus, its price decision in period $(t+1)$ is mainly based on its reaction function and price in period $(t)$.

So, the price adjustment mechanism of firm Y can be written as follows:

$$
p_{y_{t+1}}=(1-\beta) p_{y_{t}}+\beta p_{y_{t}}^{*}
$$

where $\beta>0$ represents the adjustment speed of firm Y.
Assumption 10. Firm $\mathrm{Z}$ has simple rationality; that is, its price decision in period $(t+1)$ is mainly based on its optimal reaction function in period $(t)$.

Thus, the price adjustment mechanism of firm $\mathrm{Z}$ can be expressed as follows:

$$
p_{z_{t+1}}=p_{z_{t}}^{*}
$$

So, the repeated price game of irrigation water in the coastal irrigation district has the following nonlinear form:

$$
\begin{aligned}
& p_{x_{t+1}}=p_{x_{t}}+\alpha p_{x_{t}}\left(a-2 b p_{x_{t}}+d\left(p_{y_{t}}+p_{z_{t}}\right)+b c_{1}\right) \\
& p_{y_{t+1}}=(1-\beta) p_{y_{t}}+\frac{\beta}{2 b}\left(a+d\left(p_{x_{t}}+p_{z_{t}}\right)+b\left(c_{2}-s_{2}\right)\right) \\
& p_{z_{t+1}}=\frac{1}{2 b}\left(a+d\left(p_{x_{t}}+p_{y_{t}}\right)+b\left(c_{3}-s_{3}\right)\right) .
\end{aligned}
$$

In what follows, we will focus on how the government supports intensities $s_{2}$ and $s_{3}>0$ which have an effect on the complex dynamics of the irrigation water price game.

\section{Stability of Fixed Points}

The fixed points of the system (11) satisfy the following algebraic system:

$$
\begin{aligned}
& p_{x}+\alpha p_{x}\left(a-2 b p_{x}+d\left(p_{y}+p_{z}\right)+b c_{1}\right)=0, \\
& (1-\beta) p_{y}+\frac{\beta}{2 b}\left(a+d\left(p_{x}+p_{z}\right)+b\left(c_{2}-s_{2}\right)\right)=0, \\
& \frac{1}{2 b}\left(a+d\left(p_{x}+p_{y}\right)+b\left(c_{3}-s_{3}\right)\right)=0 .
\end{aligned}
$$

By simple computation, one can obtain two fixed points $E_{0}=$ $\left(p_{x_{0}}, p_{y_{0}}, p_{z_{0}}\right)$ and $E_{1}=\left(p_{x_{1}}, p_{y_{1}}, p_{z_{1}}\right)$, where

$$
\begin{gathered}
p_{x_{0}}=0, \\
p_{y_{0}}=\frac{a d+b d c_{3}-b d s_{3}+2 a b+2 b^{2} c_{2}-2 b^{2} s_{2}}{4 b^{2}-d^{2}}, \\
p_{z_{0}}=\frac{2 a b+2 b^{2} c_{3}-2 b^{2} s_{3}+a d+b d c_{2}-b d s_{2}}{4 b^{2}-d^{2}}, \\
p_{x_{1}}=\frac{a d+2 b\left(a+b c_{1}\right)-b d\left(c_{1}-c_{2}-c_{3+s_{2}}+s_{3}\right)}{2(2 b+d)(b-d)}, \\
p_{y_{1}}=\frac{2 b^{2}\left(c_{2}-s_{2}\right)+b d\left(c_{1}-s_{3}-c_{2+c_{3}}+s_{2}\right)+a(2 b+d)}{2(2 b+d)(b-d)}, \\
p_{z_{1}}=\frac{2 b^{2}\left(c_{3}-s_{3}\right)+b d\left(c_{1}+c_{2}-c_{3}-s_{2}+s_{3}\right)+a(2 b+d)}{2(2 b+d)(b-d)} .
\end{gathered}
$$

If the characteristic polynomial of a 3-order square matrix can be written as

$$
P(\lambda)=(\lambda)^{3}+a_{2} \lambda^{2}+a_{1} \lambda+a_{0}=0,
$$


then one can get directly the following Lemma 11 from the Jury stability criterion.

Lemma 11. A necessary and sufficient condition that the characteristic polynomial of a matrix $A=\left(a_{i j}\right)_{3 \times 3}$ has all of its roots inside the unit circle is that

$$
\begin{gathered}
1+a_{0}+a_{1}+a_{2}>0, \\
1-a_{0}+a_{1}-a_{2}>0, \\
1-a_{0}^{2}>\left|a_{1}-a_{0} a_{2}\right|, \\
\left|a_{0}\right|<1 .
\end{gathered}
$$

3.1. Stability of $E_{0}$. The Jacobian matrix of system (11) at the point $E_{0}$ can be written as

$$
A\left(E_{0}\right)=\left[\begin{array}{ccc}
1+\alpha\left(a+d\left(y_{0}+z_{0}\right)+b c_{1}\right) & 0 & 0 \\
\frac{\beta d}{2 b} & 1-\beta & \frac{\beta d}{2 b} \\
\frac{d}{2 b} & \frac{d}{2 b} & 0
\end{array}\right] .
$$

Its characteristic polynomial can be written as

$$
P(\lambda)=(\lambda)^{3}+A_{2} \lambda^{2}+A_{1} \lambda+A_{0}=0,
$$

where $A_{2}=\beta-\alpha\left(a+d y_{0}+d z_{0}+b c_{1}\right)-2, A_{1}=\alpha(1-$ $\beta) b c_{1}+\left(\left(y_{0}+z_{0}\right)(1-\beta) d+a(1-\beta)\right) \alpha+1-\beta-\left(\beta d^{2} / 4 b^{2}\right)$, and $A_{0}=\left(-1-\alpha \beta\left(a+d\left(y_{0}+z_{0}\right)+b c 1\right)\right) d^{2} / 4 b^{2}$.

From Lemma 11, one can get the locally asymptotically stable region $\Omega_{E_{0}}\left(s_{2}, s_{3}\right)$ with respect to parameters $\left(s_{2}, s_{3}\right)$ as follows:

$$
\begin{aligned}
\Omega_{E_{0}}\left(s_{2}, s_{3}\right)=\{ & \left(s_{2}, s_{3}\right): 1+A_{0}+A_{1}+A_{2}>0, \\
& 1-A_{0}+A_{1}-A_{2}>0, \\
& \left.1-A_{0}^{2}>\left|A_{1}-A_{0} A_{2}\right|,\left|A_{0}\right|<1\right\} .
\end{aligned}
$$

3.2. Stability of $E_{1}$. The Jacobian matrix of system (11) at the point $E_{1}$ has the following form:

$$
\begin{aligned}
& A\left(E_{1}\right) \\
& =\left[\begin{array}{ccc}
1+\alpha \alpha-4 \alpha b p_{x_{1}}+\alpha d p_{y_{1}}+\alpha d p_{z_{1}}+\alpha b c_{1} & \alpha d p_{x_{1}} & \alpha d p_{x_{1}} \\
\frac{\beta d}{2 b} & 1-\beta & \frac{\beta d}{2 b} \\
\frac{d}{2 b} & \frac{d}{2 b} & 0
\end{array}\right] .
\end{aligned}
$$

Its characteristic polynomial can be written as

$$
P(\lambda)=(\lambda)^{3}+a_{2} \lambda^{2}+a_{1} \lambda+a_{0}=0,
$$

where $a_{0}=W_{5}\left(W_{4}\left(s_{2}+s_{3}\right)+W_{1}+W_{2}+W_{3}\right), a_{1}=W_{5}\left(W_{11}\left(s_{2}+\right.\right.$ $\left.\left.s_{3}\right)+W_{6}+W_{7}+W_{8}+W_{9}+W_{10}\right), a_{2}=W_{5}\left(W_{13}\left(s_{2}+s_{3}\right)+W_{12}\right)$, $W_{0}=c_{1}-c_{2}-c_{3}, W_{1}=\beta\left(\alpha b W_{0}-a \alpha-1\right) d^{4}, W_{2}=(((1-$ $\left.4 \beta) a \alpha-\beta)-\left(\left(2 c_{2}+2 c_{3}\right) \beta+W_{0}\right) \alpha b\right) b d^{3}, W_{3}=\left(2(1-2 \beta) \alpha b^{3} c_{1}+\right.$ $\left.((1-2 \beta) 2 a \alpha+2 \beta) b^{2}\right) d^{2}, W_{4}=2 \alpha \beta b^{2} d^{3}-\alpha b^{2} d^{3}+\alpha \beta b d^{4}$, $W_{5}=1 /\left(8 b^{4}-4 b^{3} d-4 d^{2} b^{2}\right), W_{6}=8 \alpha(\beta-1) b^{5} c_{1}, W_{7}=$ $\left(\alpha(4-\beta) d W_{0}+8(\beta-1)(a \alpha-1)\right) b^{4}, W_{8}=2 d((2(\beta-1)(a \alpha+1)-$ $\left.\alpha(1+\beta) c_{1} d\right) b^{3}, W_{9}=\left(\left(W_{0}(\beta+1) \alpha d+2(\beta-(\beta+1) a \alpha-2)\right) b^{2} d^{2}\right.$, $W_{10}=d^{4} \beta+(\beta-\alpha(\beta+1)) a b d^{3}, W_{11}=d^{3} \alpha b^{2}+4 \alpha b^{4} d+$ $\alpha b^{2} d^{3} \beta-4 \alpha b^{4} d \beta, W_{12}=8 \alpha b^{5} c_{1}+4\left(2 a \alpha+2 \beta-\alpha d W_{0}-4\right) b^{4}+$ $4(2+a \alpha-\beta) d b^{3}+4(2-\beta) b^{2} d^{2}$, and $W_{13}=-4 \alpha b^{4} d$.

It is obvious that the fixed point $E_{1}$ is locally asymptotically stable if and only if Lemma 11 holds. One can get the locally asymptotically stable region $\Omega_{E_{1}}\left(s_{2}, s_{3}\right)$ with respect to parameters $\left(s_{2}, s_{3}\right)$ as follows:

$$
\begin{aligned}
\Omega_{E_{1}}\left(s_{2}, s_{3}\right)=\left\{\left(s_{2}, s_{3}\right): 1+a_{0}+a_{1}+a_{2}>0,\right. \\
1-a_{0}+a_{1}-a_{2}>0, \\
\left.1-a_{0}^{2}>\left|a_{1}-a_{0} a_{2}\right|,\left|a_{0}\right|<1\right\} .
\end{aligned}
$$

3.3. Parameter Basin with respect to $\left(s_{2}, s_{3}\right)$. Let $\alpha=0.36$, $\beta=0.2, a=6, b=2.5, c_{1}=0.1, c_{2}=0.3$, and $c_{3}=0.4$; a parameter basin with respect to the parameters $\left(s_{2}, s_{3}\right)$ is shown in Figure 2, in which the two red regions correspond to $\Omega_{E_{0}}\left(s_{2}, s_{3}\right)$ and $\Omega_{E_{1}}\left(s_{2}, s_{3}\right)$, respectively, which are asymptotically stable state, the blue region denotes stable cycles of period two, the yellow region denotes chaotic state, and the white region denotes divergence state, as shown in Table 1 .

The regions $\Omega_{E_{0}}\left(s_{2}, s_{3}\right)$ and $\Omega_{E_{1}}\left(s_{2}, s_{3}\right)$ show that the price game for irrigation water will reach the Nash equilibrium by modulating limited times with random initial prices. Obviously, $E_{0}=\left(p_{x_{0}}, p_{y_{0}}, p_{z_{0}}\right)$ is a bounded equilibrium point [46], which indicates that $p_{x_{0}}=0$; that is, free supply of irrigation water is an optimal strategy of firm $X$. But, in fact, it will never happen in the real word. Thus, $E_{0}$ is not considered in the paper. And $E_{1}=\left(p_{x_{1}}, p_{y_{1}}, p_{z_{1}}\right)$ is a Nash equilibrium point, which is practical and feasible. So, we will continue to discuss $E_{1}$ in the sections below.

\section{Codimension-Two Period-Doubling (Flip) Bifurcation}

There are many bifurcation theories [47-49] that can be used into system (11), but the Kuznetsov bifurcation theory [50] is more effective to discuss the bifurcation in system (11). In what follows, we let $\alpha=0.36, \beta=0.2, a=6, b=2.5, c_{1}=0.1$, $c_{2}=0.3$, and $c_{3}=0.4$. The system (11) can be rewritten as follows:

$$
\begin{gathered}
p_{x_{t+1}}=p_{x_{t}}+1.8 p_{x_{t}}\left(1.25-p_{x_{t}}+0.11\left(p_{y_{t}}+p_{z_{t}}\right)\right), \\
p_{y_{t+1}}=0.8 p_{y_{t}}+0.022\left(p_{x_{t}}+p_{z_{t}}\right)-0.1 s_{2}+0.27 \\
p_{z_{t+1}}=0.11\left(p_{x_{t}}+p_{y_{t}}\right)-0.5 s_{3}+1.4
\end{gathered}
$$




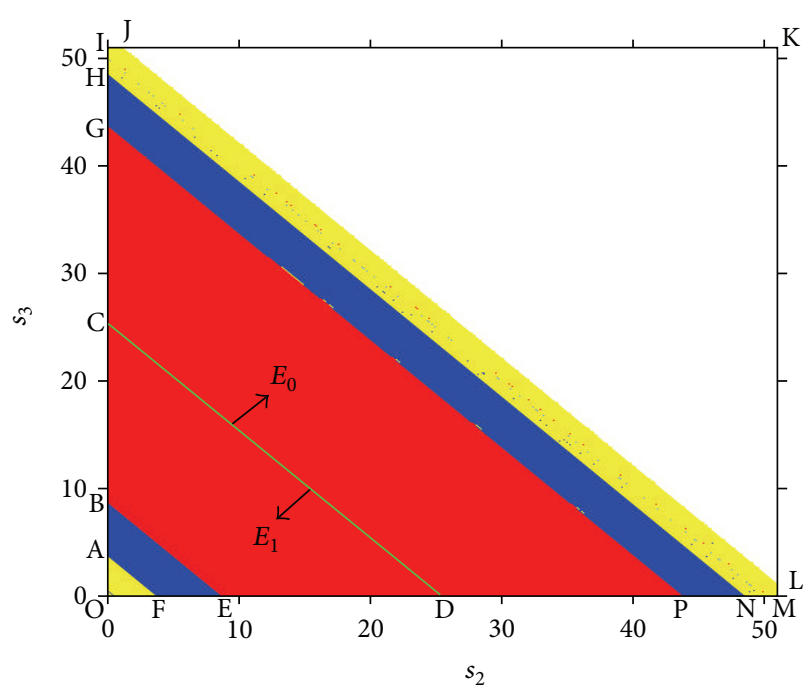

Figure 2: Parameter basin versus the parameters $\left(s_{2}, s_{3}\right)$.

TABLE 1: Legend of the color coding for Figure 2.

\begin{tabular}{|ccccc|}
\hline No. & Polyarea & Color & State type & Fixed point \\
\hline 1 & OAF & Yellow & Strange attractor & $E_{1}$ \\
\hline 2 & ABEF & Blue & Period-twocycle & $E_{1}$ \\
3 & BCDE & Red & Stable & $E_{1}$ \\
\hline 4 & CGPD & Red & Stable & $E_{0}$ \\
5 & GHNP & Blue & Period-twocycle & $E_{0}$ \\
\hline 6 & HIJLMN & Yellow & Strange attractor & $E_{0}$ \\
7 & JKL & White & Divergence & $E_{0}$ \\
\hline
\end{tabular}

Its Nash equilibrium $E_{1}=(1.096671926,1.186762016-$ $\left.0.4504504505 s_{2}, 2.580653598+0.4504504505 s_{2}\right)$. The Jacobian matrix of system (22) at the point $E_{1}$ is

$$
A_{p b}\left(E_{1}\right)=\left[\begin{array}{ccc}
-0.974 & 0.217 & 0.217 \\
0.022 & 0.8 & 0.022 \\
0.11 & 0.11 & 0
\end{array}\right]
$$

which has a simple real eigenvalue $\lambda_{1}=-1$ and other two eigenvalues $\lambda_{2}=0.0195$ and $\lambda_{3}=0.807$. From Figures 2, 3, and 4 , one can find that a period-doubling bifurcation occurs when a simple real eigenvalue $\lambda_{1}=-1$ crosses the boundary $B E$ of the stability region $\Omega_{E_{1}}\left(s_{2}, s_{3}\right)$. That is, the critical parameters values $s_{2}$ and $s_{3}$ satisfy $s_{2}+s_{3}=8.463662665$ at the boundary $B E$ of the stability region $\Omega_{E_{1}}\left(s_{2}, s_{3}\right)$.

When the fixed point $E_{1}$ loses stability via a perioddoubling bifurcation point, the restriction of system (22) to a one-dimensional center manifold at the critical parameter value can be transformed to the normal form as follows:

$$
X_{n+1}=-X_{n}+\frac{1}{6} b_{1} X_{n}^{3}+O\left(X_{n}^{4}\right), \quad X_{n} \in \mathbb{R}^{1},
$$

where $b_{1} \neq 0$ is called normal form coefficient [50], which is given by

$$
b_{1}=\frac{1}{6}\left\langle p, C(q, q, q)+3 B\left(q,\left(I_{3}-A\right)^{-1} B(q, q)\right)\right\rangle,
$$

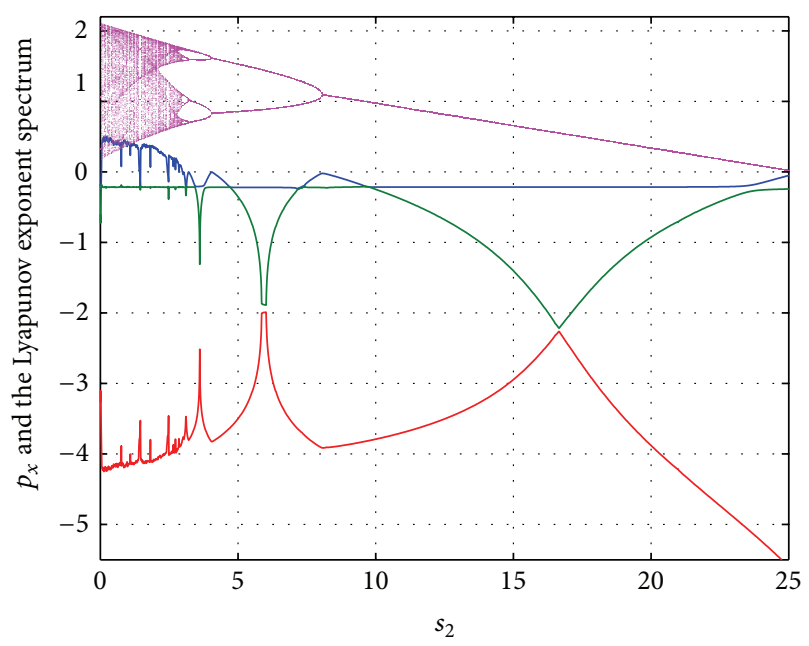

FIGURE 3: The Lyapunov exponent spectrum (blue, green, and red) and bifurcation of $p_{x}$ (pinkish red) versus the parameters $s_{2}$ when $s_{3}=0.4$.

where $I_{3}$ is the unit $3 \times 3$ matrix, $A q=-q, A^{T} p=-p$, $A=A_{p b}\left(E_{1}\right),\langle q, q\rangle=\langle p, q\rangle=1,\langle$,$\rangle denotes the inner$ product, and the multilinear functions $B$ and $C$ are defined, respectively, by

$$
\begin{gathered}
B_{i}(x, y)=\left.\sum_{j, k=1}^{n} \frac{\partial^{2} X_{i}(\xi, 0)}{\partial \xi_{j} \partial \xi_{k}}\right|_{\xi=0} x_{j} y_{k}, \quad i=1,2, \\
C_{i}(x, y, z)=\left.\sum_{j, k, l=1}^{n} \frac{\partial^{3} X_{i}(\xi, 0)}{\partial \xi_{j} \partial \xi_{k} \partial \xi_{l}}\right|_{\xi=0} x_{j} y_{k} z_{l}, \quad i=1,2 .
\end{gathered}
$$

For the system (22),

$$
\begin{gathered}
q=(-0.994075101,0.01082788553,0.1081571934)^{T}, \\
p=(-0.9818661631,0.1055591755,0.2108811391)^{T}, \\
B(\xi, \eta)=\left(\begin{array}{c}
0.198\left(\xi_{1} \eta_{2}+\xi_{1} \eta_{3}+\xi_{2} \eta_{1}+\xi_{3} \eta_{1}\right)-3.6 \xi_{1} \eta_{1} \\
0 \\
0
\end{array}\right), \\
C(\xi, \eta, \zeta)=\left(\begin{array}{l}
0 \\
0 \\
0
\end{array}\right) .
\end{gathered}
$$

One can obtain

$$
\begin{gathered}
B(q, q)=\left(\begin{array}{c}
-3.604306026 \\
0 \\
0
\end{array}\right), \\
B\left(q,\left(I_{3}-A\right)^{-1} B(q, q)\right)=\left(\begin{array}{c}
-6.669763092 \\
0 \\
0
\end{array}\right), \\
C(q, q, q)=\left(\begin{array}{l}
0 \\
0 \\
0
\end{array}\right) .
\end{gathered}
$$




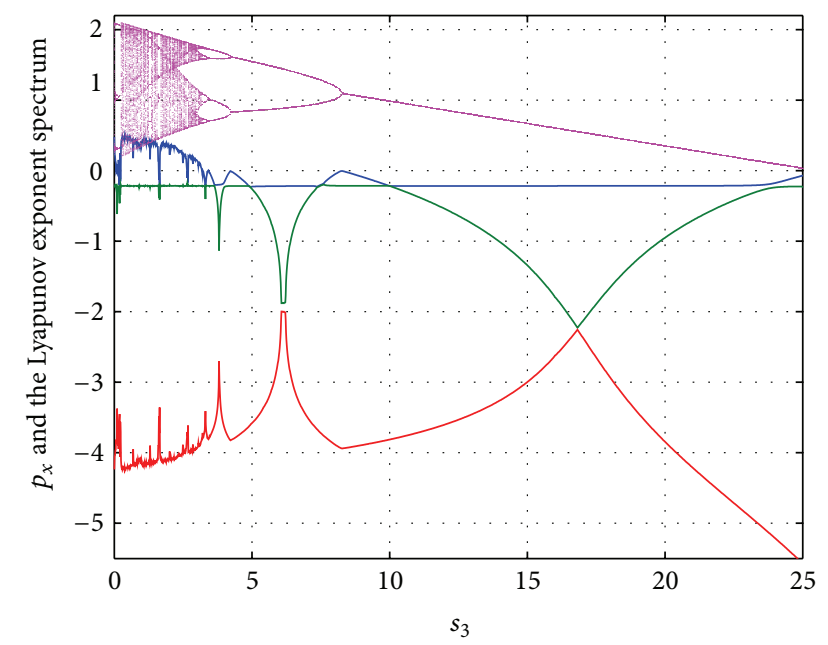

Figure 4: The Lyapunov exponent spectrum (blue, green, and red) and bifurcation of $p_{x}$ (pinkish red) versus the parameters $s_{3}$ when $\mathrm{s}_{2}=0.2$.

So, the critical normal form coefficient

$$
b_{1}=3.274406>0
$$

which means that the period-doubling bifurcation at the fixed point $E_{1}$ is supercritical.

\section{Numerical Simulation}

From Figures 3 and 4, it can be observed that there is a very good agreement between the bifurcation diagram and the Lyapunov exponent spectrum. What is more, it can be find that the Lyapunov exponent spectrum and the bifurcation diagrams in Figures 3 and 4 well coincide with the parameter basin diagram in Figure 2, respectively. In this section, the numerical bifurcation and chaos will be employed to verify the above main results.

5.1. Numerical Bifurcation. In this subsection, based on continuation methods [51], we will discuss numerical bifurcations by using the MATLAB package Cl_MatContM [39-43].

Firstly, we consider that $E_{1}=(1.596211596,1.596211596$, 1.551166551) which is in the stable region BCDE of Figure 2. We do a numerical continuation of $E_{1}$ with $s_{2}$ free, and $s_{3}=$ 0.4 fixed, as shown in Figure 5 and Table 2. Switchings at PD points of the second and fourth iterates are given in Figure 6.

Secondly, from the fixed point $E_{1}=(1.596211596$, $1.596211596,1.551166551)$, we do a numerical continuation of $E_{1}$ with $s_{2}=0.2$ fixed and $s_{3}$ free, as shown in Figure 7 and Table 3.

In Tables 2 and 3, the first three entries of $x$ are the coordinate values of the fixed point $E_{1}$, and the last entry of $x$ is the value of the free parameters $s_{2}$ or $s_{3}$ at the corresponding bifurcation point. It is obvious that the normal form coefficient of the PD point is 3.274406, confirming (29). What is more, the detected bifurcation points in Figures 5 and 6 are in accordance with the statement in Figure 2. In

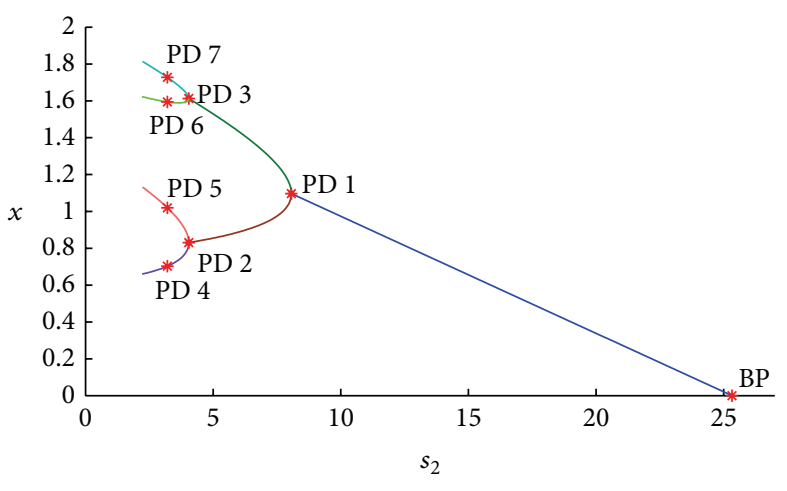

Figure 5: Continuation of $E_{1}$ in $\left(s_{2}, x\right)$-space.

addition, the label "PD" means that a period-doubling (flip) bifurcation occurs. In Table 2 , the critical point "2-cycle" means that a stable 2 -cycle is born when $s_{2}<8.063663$, "4cycle" means that a stable 4 -cycle is born when $s_{2}<4.045975$, and so on.

5.2. Numerical Chaos. In the above section, the Wolf algorithm [52] is employed to calculate the Lyapunov exponent spectrum shown in Figures 3 and 4, by which one can find chaos when a largest Lyapunov exponent is greater than 0 . In this section, we will use a reliable and efficient binary test for the chaos (called "0-1 test") to detect chaotic attractors.

5.2.1. The 0-1 Test Algorithm. The 0-1 test algorithm [33-38] can be described as follows.

Consider a discrete set of measurement data $\phi(n)$ sampled at times $n=1,2,3, \ldots, N$, where $N$ is the amount of the data.

Step 1. Choose a random number $c \in(\pi / 5,4 \pi / 5)$, and define the following new coordinates $\left(p_{c}(n), s_{c}(n)\right)$ :

$$
\begin{aligned}
& p_{c}(n)=\sum_{j=1}^{n} \phi(j) \cos (\theta(j)), \\
& s_{c}(n)=\sum_{j=1}^{n} \phi(j) \sin (\theta(j)),
\end{aligned}
$$

where

$$
\theta(j)=j c+\sum_{i=1}^{j} \phi(j), \quad j=1,2,3, \ldots, n .
$$

Step 2. Define the mean square displacement $M_{c}(n)$ as follows:

$$
\begin{aligned}
M_{c}(n)= & \lim _{N \rightarrow \infty} \frac{1}{N} \sum_{j=1}^{N}\left(p_{c}(j+n)-p_{c}(j)\right)^{2} \\
& +\left(s_{c}(j+n)-s_{c}(j)\right)^{2}, \quad n \in\left[1, \frac{N}{10}\right] .
\end{aligned}
$$


TABLE 2: Numerical continuation of $E_{1}$ with control parameter $s_{2}$ as shown in Figure 5.

\begin{tabular}{|c|c|c|c|c|}
\hline No. & Label & $x$ & Normal form coefficient & Critical point \\
\hline 1 & $\mathrm{PD}$ & $(1.096672-2.4451801 .0516278 .063663)$ & $3.274406 e+00$ & 2-cycle \\
\hline 2 & $\mathrm{PD}$ & $(0.830878-0.3923611 .3332794 .045975)$ & $1.868612 e+01$ & 4-cycle \\
\hline 3 & $\mathrm{PD}$ & $(1.612503-0.4008751 .2482374 .045975)$ & $9.352670 e+01$ & 4-cycle \\
\hline 4 & PD & $(0.7026440 .0389911 .3931753 .208909)$ & $5.559248 e+02$ & 8-cycle \\
\hline 5 & $\mathrm{PD}$ & $\left(\begin{array}{llll}1.019443 & 0.033503 & 1.378263 & 3.208909\end{array}\right)$ & $1.160791 e+02$ & 8 -cycle \\
\hline 6 & $\mathrm{PD}$ & $\left(\begin{array}{llll}1.594166 & 0.026410 & 1.281580 & 3.208909\end{array}\right)$ & $5.498331 e+02$ & 8 -cycle \\
\hline 7 & $\mathrm{PD}$ & (1.727479 0.0286611 .3158243 .208909$)$ & $3.265258 e+03$ & 8-cycle \\
\hline
\end{tabular}

TABLE 3: Numerical continuation of $E_{1}$ with control parameter $s_{3}$ as shown in Figure 6.

\begin{tabular}{|c|c|c|c|c|}
\hline No. & Label & $x$ & Normal form coefficient & Critical point \\
\hline 1 & $\mathrm{PD}$ & $\left(\begin{array}{llll}1.096672 & 1.096672 & -2.490564 & 8.263663\end{array}\right)$ & $3.274406 e+00$ & 2-cycle \\
\hline 2 & $\mathrm{PD}$ & $(0.8308781 .340060-0.3991424 .245975)$ & $1.868612 e+01$ & 4-cycle \\
\hline 3 & $\mathrm{PD}$ & $(1.6125031 .331546-0.4841844 .245975)$ & $9.352670 e+01$ & 4-cycle \\
\hline 4 & $\mathrm{PD}$ & (0.702644 1.3943550 .0378113 .408909$)$ & $5.559248 e+02$ & 8 -cycle \\
\hline 5 & $\mathrm{PD}$ & 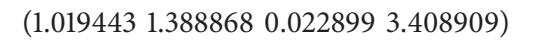 & $1.160791 e+02$ & 8 -cycle \\
\hline 6 & $\mathrm{PD}$ & $(1.5941661 .381774-0.0737843 .408909)$ & $5.498331 e+02$ & 8 -cycle \\
\hline 7 & $\mathrm{PD}$ & $(1.7274791 .384026-0.0395403 .408909)$ & $3.265258 e+03$ & 8-cycle \\
\hline
\end{tabular}

Step 3. Define the modified mean square displacement $D_{c}(n)$ as follows:

$$
D_{c}(n)=M_{c}(n)-\left(\lim _{N \rightarrow \infty} \frac{1}{N} \sum_{j=1}^{N} \phi(j)\right)^{2} \frac{1-\cos n c}{1-\cos c},
$$

Step 4. Define the median value of correlation coefficient $K$ as follows:

$$
K=\operatorname{median}\left(K_{c}\right)
$$

where

$$
K_{c}=\frac{\operatorname{cov}(\xi, \Delta)}{\sqrt{\operatorname{var}(\xi) \operatorname{var}(\Delta)}} \in[-1,1],
$$

in which $\xi=\left(1,2,3, \ldots, n_{\text {cut }}\right), \Delta=\left(D_{c}(1), D_{c}(2), \ldots\right.$, $\left.D_{c}\left(n_{\text {cut }}\right)\right), n_{\text {cut }}=\operatorname{round}(N / 10)$, and the covariance and variance are defined with vectors $x, y$ of length $q$ as follows:

$$
\begin{aligned}
& \operatorname{cov}(x, y)=\frac{1}{q} \sum_{j=1}^{q}(x(j)-\bar{x})(y(j)-\bar{y}), \\
& \bar{x}=\frac{1}{q} \sum_{j=1}^{q} x(j), \quad \operatorname{var}(x)=\operatorname{cov}(x, x) .
\end{aligned}
$$

Step 5. Interpret the outputs as follows:

(1) $K \approx 0$ indicates that the underlying dynamics is regular (i.e., periodic or quasiperiodic), whereas $K \approx$ 1 indicates that the underlying dynamics is chaotic;

(2) bounded trajectories in the $(p, s)$-plane imply that the underlying dynamics is regular, whereas the Brownian-like (unbounded) trajectories imply that the underlying dynamics is chaotic.

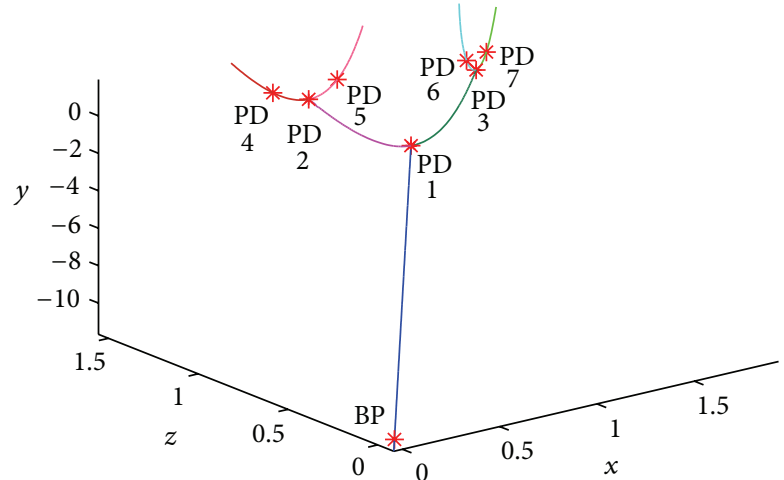

FIGURE 6: Curves of fixed points of the 1st, 2nd, and 4th iterates.

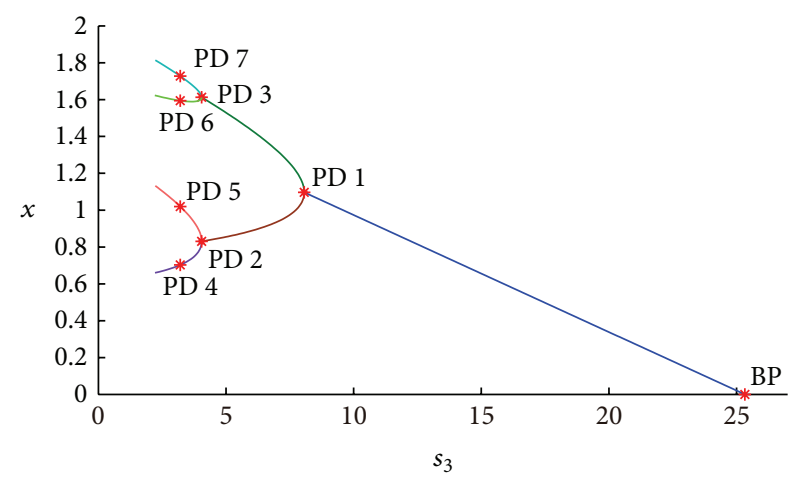

Figure 7: Continuation of $E_{1}$ in $\left(s_{3}, x\right)$-space.

5.2.2. Application. We use the data set $p_{x}$ of the system (22) to implement the $0-1$ test with $s_{2}$ and $s_{2}$, respectively. The new 


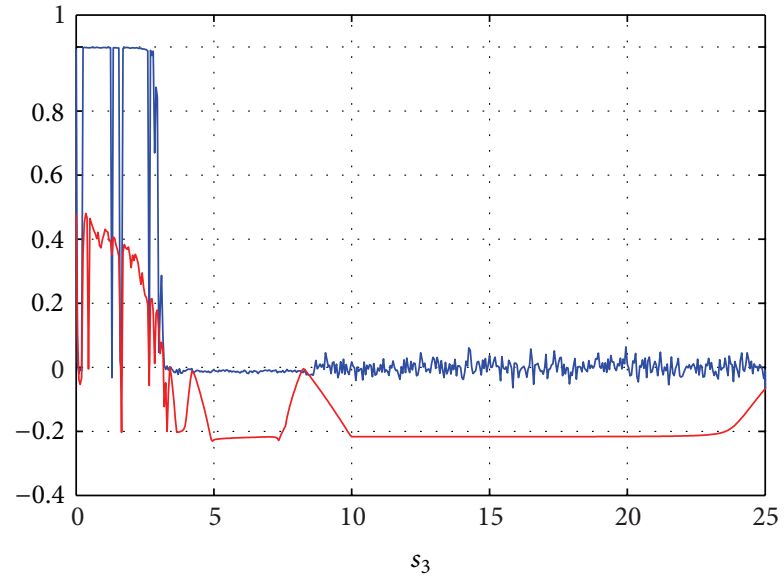

$-K$

_ The largest Lyapunov exponent

FIGURE 8: $K$ and the largest Lyapunov exponent versus $s_{3} \in[0,25]$ and $s_{2}=0.2$.

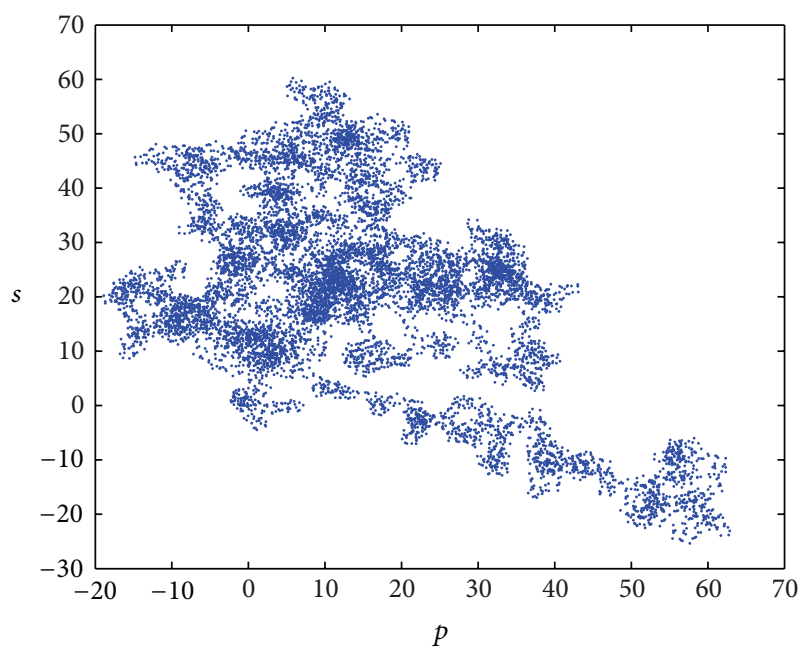

Figure 9: Plots versus $s_{2}=0.2$ and $s_{3}=1$ in new coordinates $(p, s)$ space.

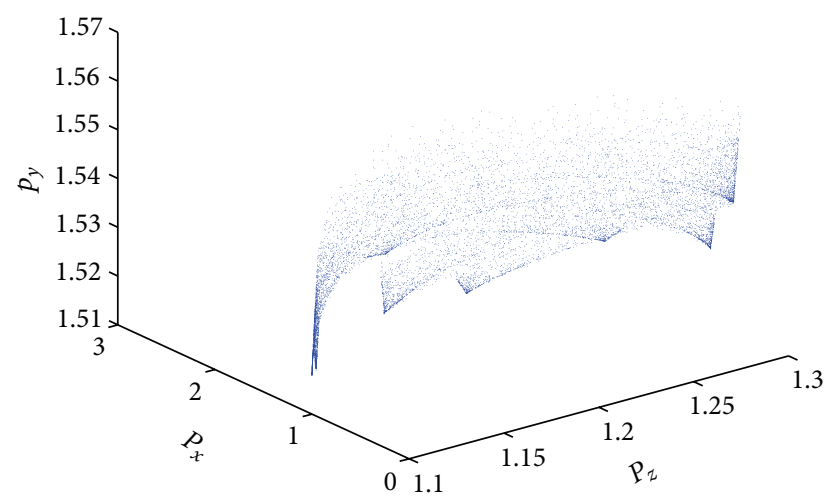

FIGURE 10: Plots versus $s_{2}=0.1$ and $s_{3}=1$ in the original state space.

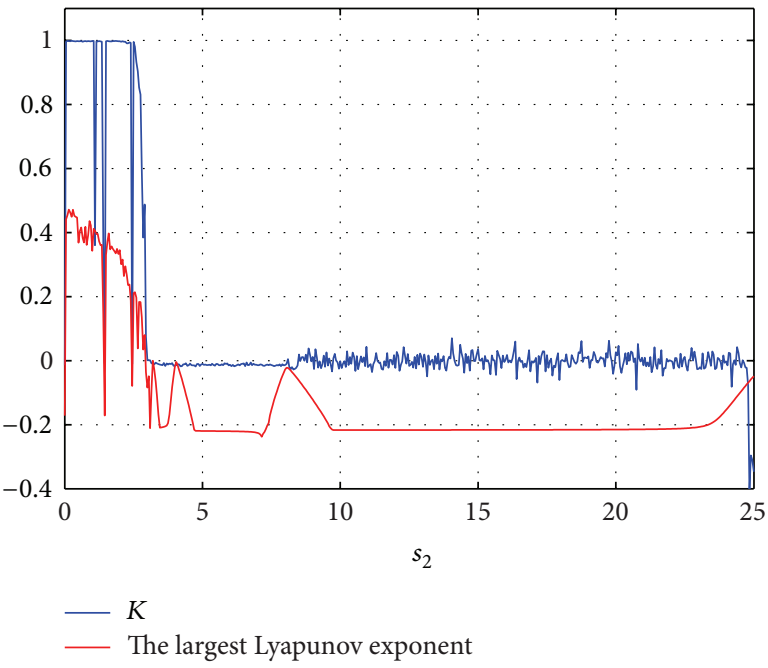

FiguRE 11: $K$ and the largest Lyapunov exponent versus $s_{2} \in[0,25]$ and $s_{3}=0.4$.

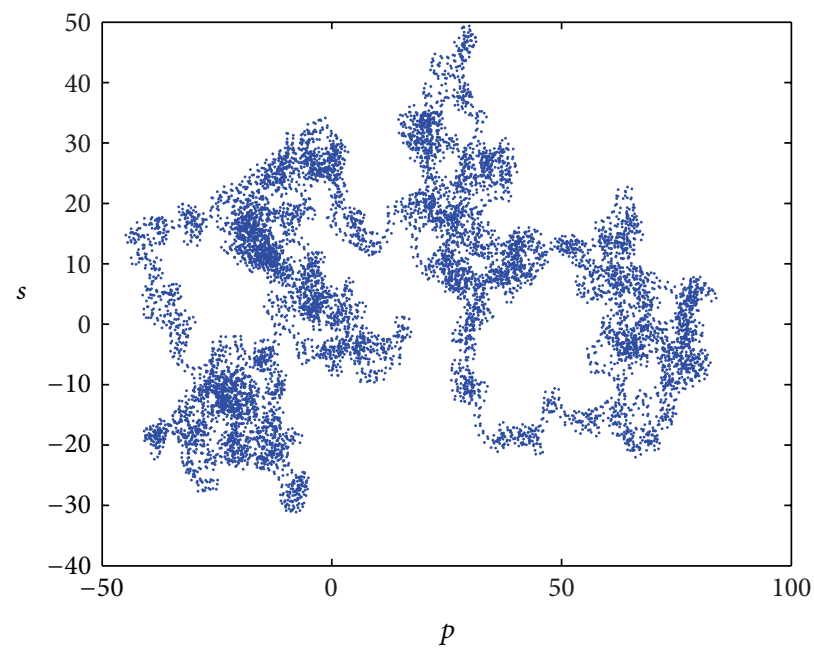

Figure 12: Plots versus $s_{2}=0.1$ and $s_{3}=0.4$ in new coordinates $(p, s)$ space.

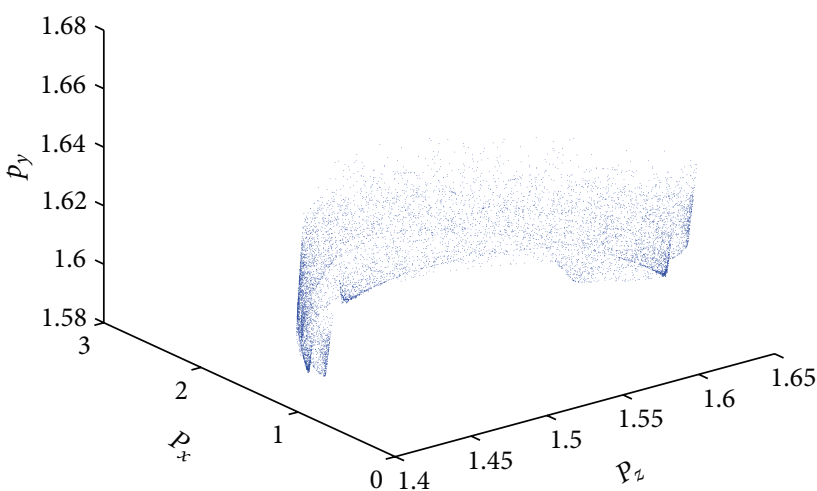

FIGURE 13: Plots versus $s_{2}=0.1$ and $s_{3}=0.4$ in the original state space. 
coordinates variables $(p, s)$ are shown in Figures 8, 9, 10, 11, 12, and 13.

When $s_{2}=0.2$ is fixed and $s_{3}$ varies from 0 to 25 in increments of 0.05 , one can get the diagram of $K$ value as shown in Figure 8, which is consistent with the numerical simulation in the above sections. If $s_{3}=1$, then $K \approx 1$, which means that the system is chaotic as shown in Figures 9 and 10.

Similarly, fixing $s_{3}=0.4$ and varying $s_{2}$ from 0 to 25 in increments of 0.05 , one can get the diagram of $K$ value as shown in Figure 11, which well coincides with the numerical simulation in the above sections. If $s_{2}=0.1$, then $K \approx 1$, which means that the system is chaotic as shown in Figures 12 and 13.

From Figures 8 and 11, it can be observed that there is a very good agreement between the largest Lyapunov exponent and the median value of correlation coefficient $K$.

\section{Conclusion}

In this paper, we have proposed a nonlinear discrete price game model of irrigation water in a coastal irrigation district. Its stability and codimension-two period-doubling (flip) bifurcation are emphatically discussed. Based on continuation methods, its numerical bifurcations are analyzed by using the MATLAB package $\mathrm{Cl}$ MatContM. Its numerical chaos is shown by means of the $0-1$ test algorithm.

\section{Acknowledgments}

This work is supported partly by the Excellent Young Scientist Foundation of Shandong Province (Grant no. BS2011SF018), the National Social Science Foundation of China (Grant no. 12BJY103), the Humanities and Social Sciences Foundation of the Ministry of Education of China (Grant no. 11YJCZH200), and the National Natural Science Foundation of China (Grant no. 71272148 ).

\section{References}

[1] D. Merrey, R. Meinzen-Dick, P. Mollinga, and E. Karar, "Policy and institutional reform processes for sustainable agricultural water management: the art of the possible," in Water for Food Water for Life: A Comprehensive Assessment of Water Management in Agriculture, D. Molden, Ed., pp. 193-232, Earthscan, London, UK, 2007.

[2] R. Meinzen-Dick, "Beyond panaceas in water institutions," Proceedings of the National Academy of Sciences of the United States of America, vol. 104, no. 39, pp. 15200-15205, 2007.

[3] W. Shaw, Water Resource Economics And Policy: An Introduction, Edward Elgar, Cheltenham, UK, 2005.

[4] R. Griffin, Water Resource Economics: The Analysis of Scarcity, Policies, and Projects, MIT Press, Cambridge, Mass, USA, 2006.

[5] R. Johansson, Y. Tsur, T. Roe, R. Doukkali, and A. Dinar, "Pricing irrigation water: a review of theory and practice," Water Policy, vol. 4, no. 2, pp. 173-199, 2002.

[6] K. Schoengold, "Irrigation water pricing: the gap between theory and practice," American Journal of Agricultural Economics, vol. 92, no. 5, pp. 1497-1498, 2010.
[7] B. Xin, J. Ma, and Q. Gao, "Complex dynamics of an adnascenttype game model," Discrete Dynamics in Nature and Society, vol. 2008, Article ID 467972, 12 pages, 2008.

[8] B. Xin and T. Chen, "Master-slave bertrand game model," Economic Modelling, vol. 28, no. 4, pp. 1864-1870, 2011.

[9] W. Ji and D. Xu, "Complexity of discrete investment competition model based on heterogeneous participants," International Journal of Computer Mathematics, vol. 89, no. 4, pp. 492-498, 2012.

[10] T. Puu, "Chaos in business cycles," Chaos, Solitons and Fractals, vol. 1, no. 5, pp. 457-473, 1991.

[11] G. Bischi, A. Naimzada, and L. Sbragia, "Oligopoly games with local monopolistic approximation," Journal of Economic Behavior \& Organization, vol. 62, no. 3, pp. 371-388, 2007.

[12] H. N. Agiza and A. A. Elsadany, "Nonlinear dynamics in the Cournot duopoly game with heterogeneous players," Physica A, vol. 320, no. 1-4, pp. 512-524, 2003.

[13] J. Wouter and H. Den, "The importance of the number of different agents in a heterogeneous asset-pricing model," Journal of Economic Dynamics \& Control, vol. 25, no. 5, pp. 721-746, 2001.

[14] A. Elsadany, "Competition analysis of a triopoly game with bounded rationality," Chaos Solitons \& Fractals, vol. 45, no. 11, pp. 1343-1348, 2012.

[15] W. Ji, "Chaos and control of game model based on heterogeneous expectations in electric power triopoly," Discrete Dynamics in Nature and Society, vol. 2009, Article ID 469564, 8 pages, 2009.

[16] Y. Son, R. Baldick, K. Lee, and S. Siddiqi, "Short-term electricity market auction game analysis: uniform and pay-as-bid pricing," IEEE Transactions on Power Systems, vol. 19, pp. 1990-1998, 2004.

[17] C. C. Skoulidas, C. D. Vournas, and G. P. Papavassilopoulos, "An adaptive learning game model for interacting electric power markets," Infor, vol. 48, no. 4, pp. 261-266, 2010.

[18] L. Mu, P. Liu, Y. Li, and J. Zhang, "Complexity of a real estate game model with a nonlinear demand function," International Journal of Bifurcation and Chaos, vol. 21, no. 11, pp. 3171-3179, 2011.

[19] L. Mu, J. Ma, and L. Chen, "A 3-dimensional discrete model of housing price and its inherent complexity analysis," Journal of Systems Science \& Complexity, vol. 22, no. 3, pp. 415-421, 2009.

[20] X. Liu, X. Liang, and B. Tang, "Minority game and anomalies in financial markets," Physica A, vol. 333, pp. 343-352, 2004.

[21] K. Gkonis and H. Psaraftis, "The LNG market: a game theoretic approach to competition in LNG shipping," Maritime Economics \& Logistics, vol. 11, pp. 227-246, 2009.

[22] Z. Sun and J. Ma, "Complexity of triopoly price game in Chinese cold rolled steel market," Nonlinear Dynamics, vol. 67, no. 3, pp. 2001-2008, 2012.

[23] S. Sugawara and Y. Omori, "Duopoly in the Japanese airline market: bayesian estimation for the entry game," The Japanese Economic Review, vol. 63, no. 3, pp. 310-332, 2012.

[24] S. Chung, R. Weaver, and T. Friesz, "Oligopolies in pollution permit markets: a dynamic game approach," International Journal of Production Economics, vol. 140, no. 1, pp. 48-56, 2012.

[25] J. Ma and J. Zhang, "Price game and chaos control among three oligarchs with dierent rationalities in property insurance market," Chaos, vol. 22, no. 4, Article ID 043120, 2012.

[26] F. Tramontana and A. E. A. Elsadany, "Heterogeneous triopoly game with isoelastic demand function," Nonlinear Dynamics, vol. 68, no. 1-2, pp. 187-193, 2012. 
[27] J. Du, T. Huang, and Z. Sheng, "Analysis of decision-making in economic chaos control," Nonlinear Analysis, vol. 10, no. 4, pp. 2493-2501, 2009.

[28] W. Huang, "The long-run benefits of chaos to oligopolistic firms," Journal of Economic Dynamics \& Control, vol. 32, no. 4, pp. 1332-1355, 2008.

[29] J. Zhang, Q. Da, and Y. Wang, "The dynamics of Bertrand model with bounded rationality," Chaos, Solitons and Fractals, vol. 39, no. 5, pp. 2048-2055, 2009.

[30] M. Kopel, "Simple and complex adjustment dynamics in Cournot duopoly models," Chaos, Solitons and Fractals, vol. 7, no. 12, pp. 2031-2048, 1996.

[31] F. Tramontana, L. Gardini, and T. Puu, "Cournot duopoly when the competitors operate multiple production plants," Journal of Economic Dynamics \& Control, vol. 33, no. 1, pp. 250-265, 2009.

[32] F. Tramontana, "Heterogeneous duopoly with isoelastic demand function," Economic Modelling, vol. 27, no. 1, pp. 350-357, 2010.

[33] G. A. Gottwald and I. Melbourne, "On the implementation of the 0-1 test for chaos," SIAM Journal on Applied Dynamical Systems, vol. 8, no. 1, pp. 129-145, 2009.

[34] G. A. Gottwald and I. Melbourne, "On the validity of the 0-1 test for chaos," Nonlinearity, vol. 22, no. 6, pp. 1367-1382, 2009.

[35] G. Gottwald and I. Melbourne, "Comment on Reliability of the 0-1 test for chaos," Physical Review E, vol. 77, no. 2, part 2, 3 pages, 2008.

[36] I. Falconer, G. A. Gottwald, I. Melbourne, and K. Wormnes, "Application of the 0-1 test for chaos to experimental data," SIAM Journal on Applied Dynamical Systems, vol. 6, no. 2, pp. 395-402, 2007.

[37] K. Sun, X. Liu, and C. Zhu, "The 0-1 test algorithm for chaos and its applications," Chinese Physics B, vol. 19, no. 11, Article ID 110510, 2010.

[38] L. Yuan and Q. Yang, "A proof for the existence of chaos in diffusively coupled map lattices with open boundary conditions," Discrete Dynamics in Nature and Society, vol. 2011, Article ID 174376, 16 pages, 2011.

[39] W. Govaerts and A. Y. Kuznetsov, "Matcont: a Matlab software project for the numerical continuation and bifurcation study of continuous and discrete parameterized dynamical systems," http://sourceforge.net.

[40] W. Govaerts, R. K. Ghaziani, Yu. A. Kuznetsov, and H. G. E. Meijer, "Numerical methods for two-parameter local bifurcation analysis of maps," SIAM Journal on Scientific Computing, vol. 29, no. 6, pp. 2644-2667, 2007.

[41] W. Govaerts and R. K. Ghaziani, "Stable cycles in a Cournot duopoly model of Kopel," Journal of Computational and Applied Mathematics, vol. 218, no. 2, pp. 247-258, 2008.

[42] R. K. Ghaziani, W. Govaerts, and C. Sonck, "Resonance and bifurcation in a discrete-time predator-prey system with Holling functional response," Nonlinear Analysis, vol. 13, no. 3, pp. 1451-1465, 2012.

[43] R. K. Ghaziani, W. Govaerts, and C. Sonck, "Codimension-two bifurcations of fixed points in a class of discrete prey-predator systems," Discrete Dynamics in Nature and Society, vol. 2011, Article ID 862494, 27 pages, 2011.

[44] R. Gibbons, A Primer in Game Theory, Simon and Schuster, New York, NY, USA, 1992.

[45] A. Dixit, "Comparative statics for oligopoly," International Economic Review, vol. 27, no. 1, pp. 107-122, 1986.
[46] G. Bischi and M. Kopel, "Equilibrium selection in a nonlinear duopoly game with adaptive expectations," Journal of Economic Behavior \& Organization, vol. 46, pp. 73-100, 2001.

[47] G. Wen, "Criterion to identify Hopf bifurcations in maps of arbitrary dimension," Physical Review E, vol. 72, no. 2, Article ID 026201, p. 4, 2005.

[48] G. Wen, D. Xu, and X. Han, "On creation of Hopf bifurcations in discrete-time nonlinear systems," Chaos, vol. 12, no. 2, pp. 350$355,2002$.

[49] Q. Lu, Bifurcation and Singularity, Shanghai Scientific and Technological Education Publishing House, Shanghai, China, 1995.

[50] Y. A. Kuznetsov, Elements of Applied Bifurcation Theory, vol. 112 of Applied Mathematical Sciences, Springer, New York, NY, USA, 2nd edition, 1998.

[51] E. L. Allgower and K. Georg, Numerical Continuation Methods, vol. 13 of Springer Series in Computational Mathematics, Springer, Berlin, Germany, 1990.

[52] A. Wolf, J. B. Swift, H. L. Swinney, and J. A. Vastano, "Determining Lyapunov exponents from a time series," Physica D, vol. 16, no. 3, pp. 285-317, 1985. 


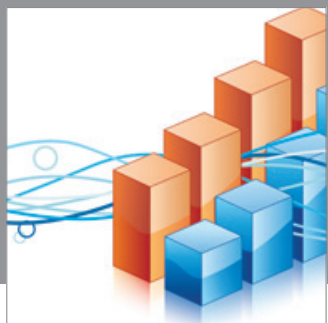

Advances in

Operations Research

mansans

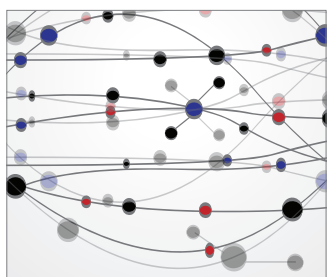

The Scientific World Journal
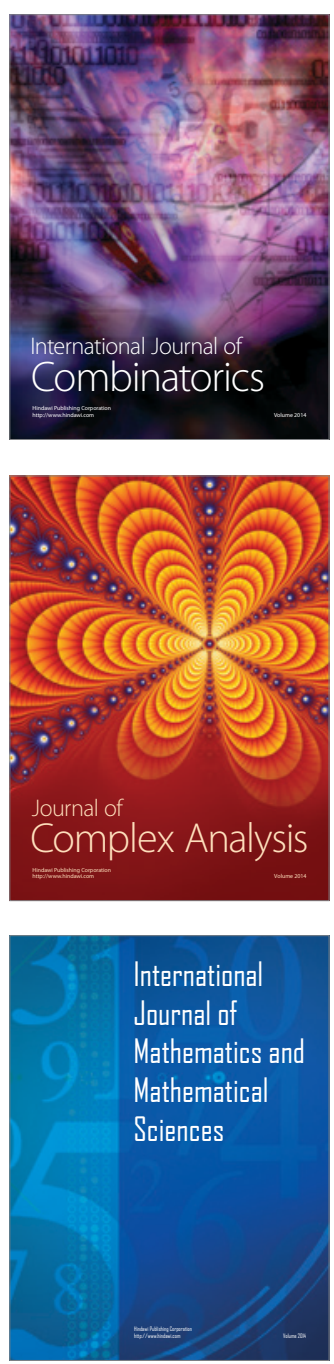
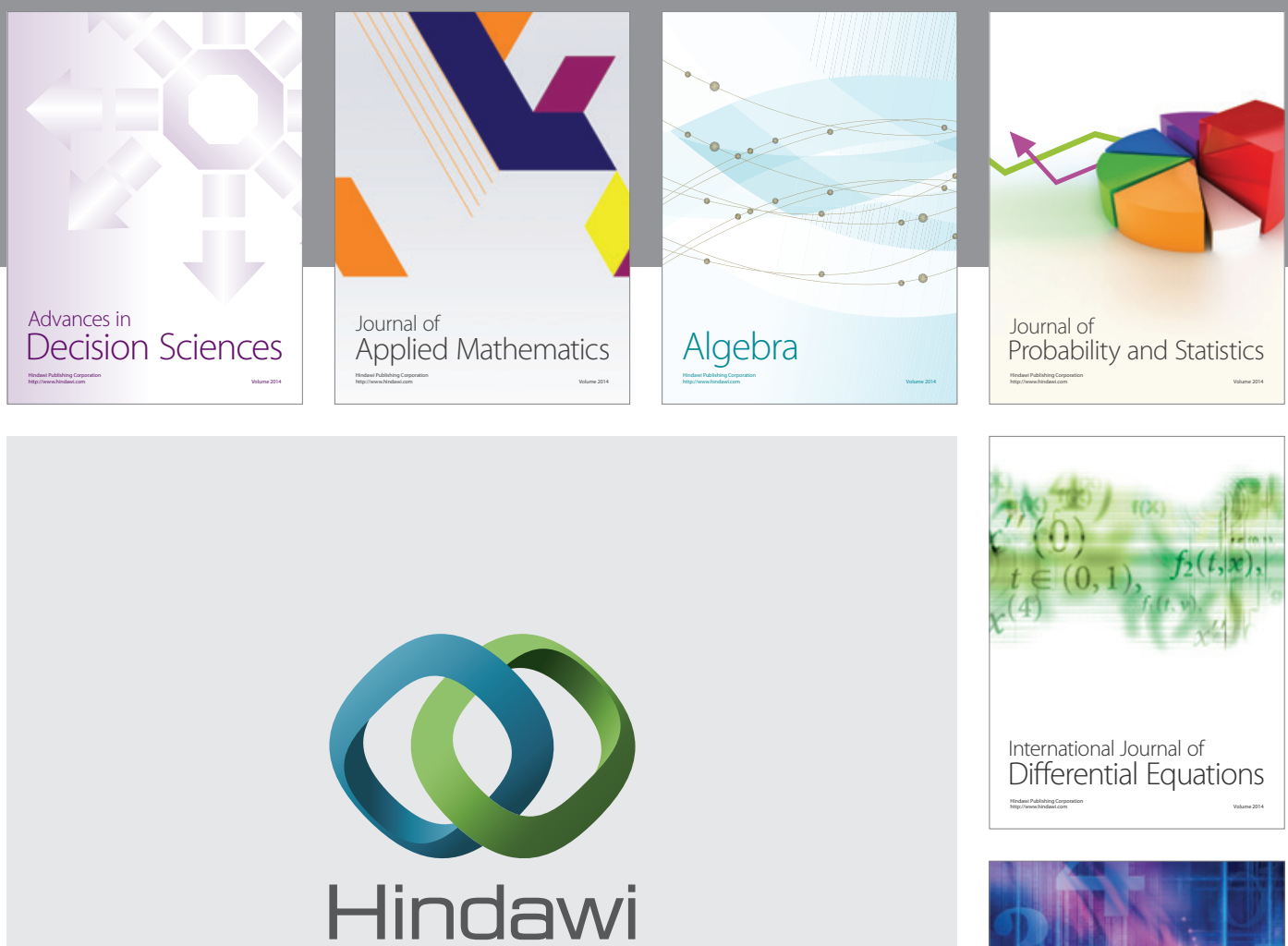

Submit your manuscripts at http://www.hindawi.com
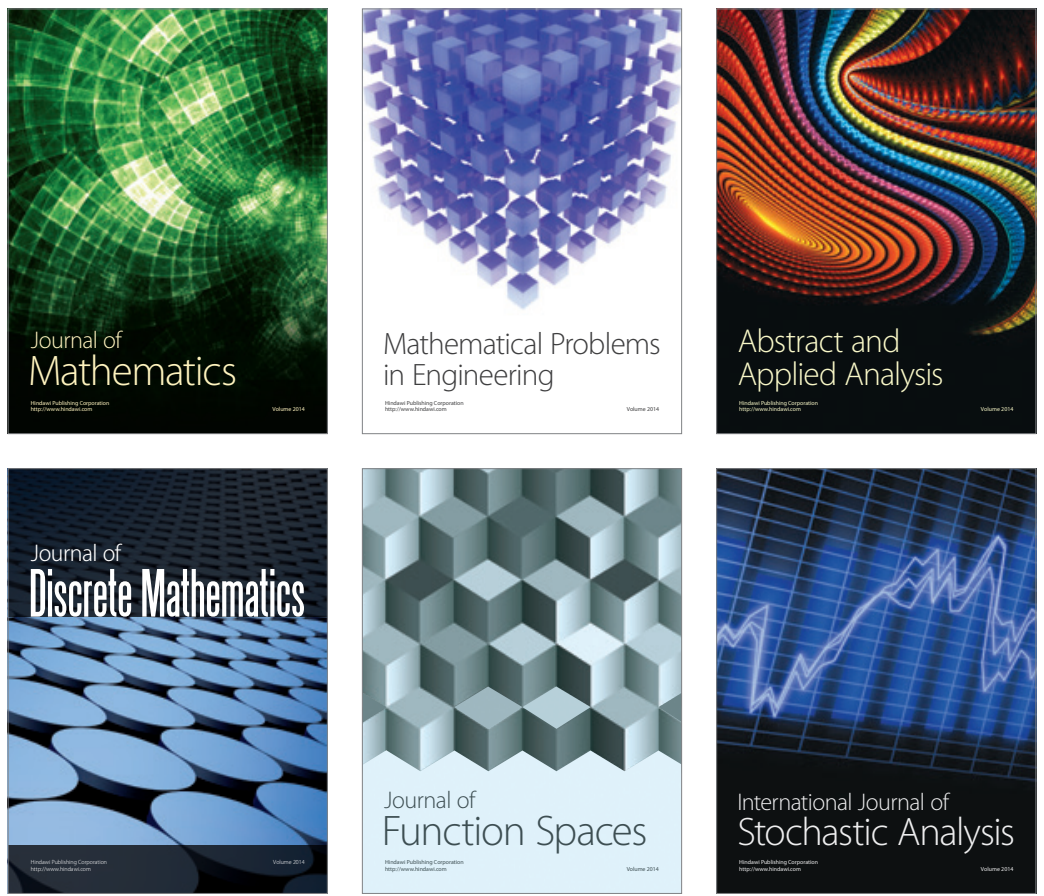

Journal of

Function Spaces

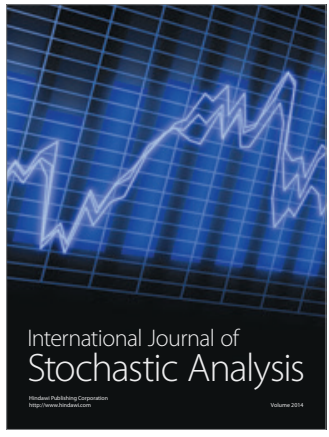

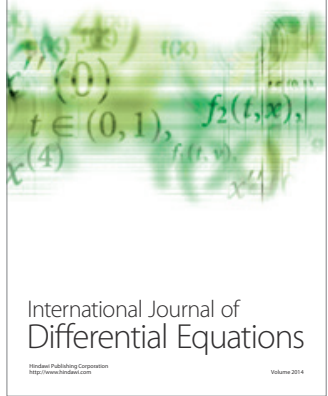
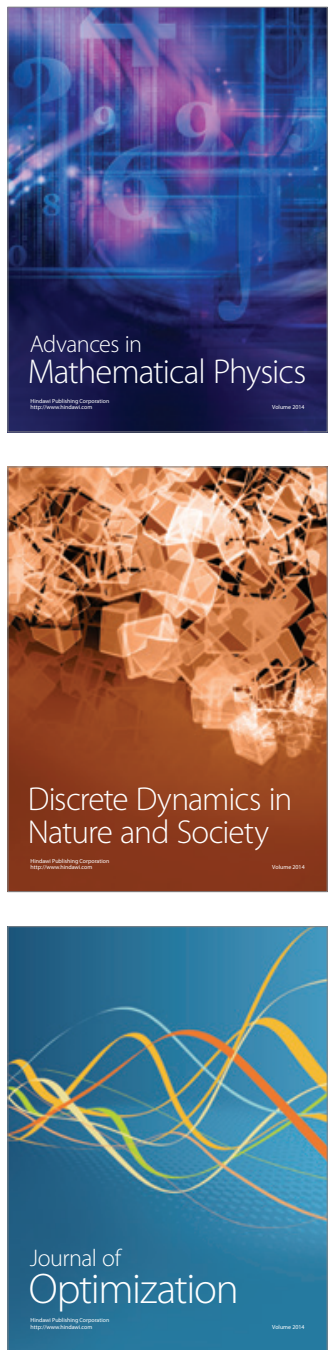